\title{
CRESCIMENTO ECONÔMICO E POPULACIONAL DA MESORREGIÃO NORTE PIONEIRO DO PARANÁ, NO PERÍODO DE 2004 A 2014
}

\author{
Fernanda Cristina Ferro Malacoski* \\ Jandir Ferrera de Lima**
}

\begin{abstract}
Resumo
O crescimento econômico é verificado quando, dado altas taxas de crescimento populacional, estiveram presente condições de manter o produto e a qualidade de vida. Este artigo teve como escopo analisar o crescimento econômico da mesorregião Norte Pioneiro do Paraná a partir da análise do Produto Interno Bruto (PIB) e do crescimento da população nos anos de 2004-2014. Para isso, foram calculados indicadores utilizando o PIB real e a população residente. Os resultados apontam que o crescimento econômico atrai população ou neutraliza o processo de emigração. Algumas microrregiões, pertencentes à mesorregião supracitada, encontraram uma forma de dinamizar sua economia propiciando crescimento sustentado.
\end{abstract}

Palavras-chave: Crescimento econômico. População. Investimento. Atração.

\footnotetext{
* Administradora e Mestre pelo Programa de Desenvolvimento Regional e Agronegócio da Unioeste - Universidade Estadual do Oeste do Paraná/Toledo. Braganey, Paraná - Brasil. Email: fer-crisferro@hotmail.com.

** Professor doutor do PGDRA e do PGE da UNIOESTE - Universidade Estadual do Oeste do Paraná/Toledo. Pesquisador do CNPQe da Fundação Araucária. Toledo, Paraná - Brasil. Email: Jandir.lima@unioeste.br.
} 


\section{Introdução}

O objetivo deste artigo é analisar o crescimento econômico da mesorregião geográfica Norte Pioneiro do Paraná, a partir da análise do Produto Interno Bruto (PIB) e do crescimento da população para o período de 2004 a 2014.

O Norte Pioneiro do Paraná foi a região com o PIB mais significativo no início do século XX. No entanto, ao final do século XX, a região estava na oitava posição entre as dez mesorregiões do Paraná em termos de PIB. Ou seja, o Norte Pioneiro perdeu posição entre as regiões paranaenses e seu dinamismo não foi suficiente para colocá-lo num novo patamar de crescimento econômico (FERRERA DE LIMA, 2010).

O reposicionamento do Norte Pioneiro na economia regional paranaense se fortaleceu na segunda metade do século XX, pois até os anos 1960 a economia paranaense era exclusivamente primária-exportadora. E, as mesorregiões Norte Central e Norte Pioneiro tinham no café e na cana-de-açúcar os produtos de base na dinamização de suas economias (PADIS, 1981). Ao final da década de 1970, a expansão da infraestrutura de transportes, a modernização da agropecuária e a integração dos mercados fortaleceram a agroindustrialização e a urbanização paranaense. Nesse período, o Norte Central Paranaense se consolida como a região mais dinâmica do interior paranaense, calcado numa economia agroindustrial e em rápida urbanização. Já a Região Metropolitana de Curitiba se fortalece como o polo central do estado do Paraná, como sua base produtiva mais adensada em capital e tecnologia (PADIS, 1981; PALUDO; BARROS, 1995). Enquanto isso, o Norte Pioneiro do Paraná ficou de fora desse processo. Assim, analisar o perfil de crescimento econômico e a dinâmica da população do Norte Pioneiro fornece elementos para compreender o ritmo da economia regional e sua tendência a um ciclo virtuoso de desenvolvimento.

Como os estudos populacionais e de desenvolvimento regional estão voltados para a realidade regional. Dentro dessa perspectiva, esta análise também se justifica pela relevância social, por propiciar entendimento sobre como as modificações da alocação da população ao longo do espaço interferem na produção regional. E pela perspectiva econômica, favorecendo o entendimento do crescimento econômico relacionado com a variável população.

A delimitação do estudo em uma região traz implicações para a análise. De acordo com Piacenti (2016), analisar a economia de uma determinada região é diferente de analisar uma economia nacional, isso porque, não existem barreiras entre as regiões em relação a bens, serviços e capital. A ausência de barreiras pode implicar em regiões que influenciam 
as demais devido a: diferenças dos recursos naturais disponíveis; mercado consumidor; ou capacitação da mão de obra.

Para isso, além desta introdução, serão apresentadas algumas concepções sobre o crescimento econômico (seção 2). A seção 3 apresenta a mesorregião geográfica Norte Pioneiro do Paraná, área de estudo, bem como algumas de suas características (as microrregiões e municípios que o compõe). Ainda na seção 3, será apresentada a metodologia utilizada para a elaboração da pesquisa. Em seguida (seção 4), serão apresentadas algumas discussões oriundas das concepções teóricas e dos dados apresentados sobre o crescimento do PIB real e da população da mesorregião. As considerações finais encerram esta pesquisa (seção 5).

\section{Elementos Teóricos}

Até a primeira metade do século XX havia certa compreensão que os termos "desenvolvimento econômico" e "crescimento econômico" eram equivalentes. No entanto, os estudos que seguiram ao longo do século XX, em especial depois dos anos 1950, demonstraram que havia diferenciação entre os termos e seus processos. Gerar crescimento econômico não significa necessariamente garantia de desenvolvimento econômico. No entanto, o crescimento econômico se faz necessário para a manutenção do desenvolvimento econômico, especialmente em economias com alto crescimento populacional.

O crescimento econômico pode ser definido como sucessivas ampliações positivas da renda real da economia. Sendo que, essa ampliação da renda real da economia não gera, necessariamente, melhorias nas condições de vida das pessoas (BERLINCK; COHEN, 1970).

$\mathrm{O}$ crescimento econômico de uma localidade também pode ser entendido como sucessivas ampliações positivas do PIB per capita, eventualmente associado ao crescimento populacional e mudanças estruturais. No caso, o crescimento econômico moderno é considerado acréscimos de insumos, ou seja, a mão de obra e o capital ou então aumento da eficiência desses fatores de produção, sem necessariamente aumentar a sua quantidade (KUZNETS, 1983).

O produto per capita real está associado à riqueza do país e retrata o desenvolvimento econômico a partir do crescimento contínuo dessa variável. Ele permite também mensurar a produtividade do trabalho de uma economia, lembrando que o PIB per capita ao longo do tempo sofre alterações, ocasionados pelos investimentos que são cíclicos. Apesar de o desenvolvimento ser mais complexo de definir do que o próprio crescimento, ele está também pautado sobre o crescimento econômico (FONSECA, 2006). 
Em outra concepção, o crescimento econômico é definido como o crescimento do PIB composto pela adição do valor pecuniário referente à produção de todos os serviços e bens finais de uma economia. $\mathrm{O}$ crescimento econômico pode ser representado também por meio da: expansão positiva da força de trabalho; da receita do país poupada e investida; e pela evolução tecnológica. Para medir o crescimento da produção total de um município é preciso analisar o comportamento das contas agregadas da localidade (MANSANO; PEREIRA, 2015).

$\mathrm{O}$ produto (per capita ou total) pode aumentar apontando que a região está passando por uma fase positiva de crescimento econômico, representando maior disponibilidade de bens e serviços à população. Esse processo de crescimento econômico depende da possibilidade de a região atrair recursos e das políticas macroeconômicas e setoriais adotadas, principalmente, pelo Governo Federal (PIACENTI, 2016).

Acrescenta-se ainda que, o crescimento econômico nem sempre representa benefícios para a sociedade. Pois pode acontecer desse crescimento ser usufruído apenas por uma pequena parcela da população, ou até mesmo, acontecer transferência dos saldos positivos para diferentes regiões (MANSANO; PEREIRA, 2015). As localidades não estão isoladas, logo, o crescimento econômico de uma região influencia o crescimento de outra (KUZNETS, 1983).

O resultado econômico positivo de cada país depende da sua especialização em atividades que oferece vantagens comparativas a partir de suas características e capacidades locais. $\mathrm{O}$ crescimento econômico de longo prazo e a transformação do crescimento em desenvolvimento é possível por meio de capital humano e das habilidades da região. $\mathrm{O}$ crescimento sustentável de uma economia acontece se as taxas de crescimento do PIB e da renda per capita da região permanecer positiva ao longo de um determinado espaço temporal (PIACENTI, 2016). Para Silva (1983), o crescimento econômico pode ser explicado por dois condicionantes: o acúmulo de capital e recursos humanos; e o aumento da produtividade dos recursos naturais, humanos e também do capital.

Regionalmente, o crescimento econômico reflete a diferenciação entre o tamanho das aglomerações e sua dinâmica. Aglomerações mais dinâmicas tendem a atrair mais população e fortalecer sua rede de cidades, criar novos mercados e fortalecer o sistema de transportes (LACOUR; GASHET, 2002).

\section{População e Crescimento Econômico}

Depois da Segunda Guerra Mundial, as discussões sobre a relação existente entre crescimento populacional e o crescimento econômico 
seguiram por duas vertentes. A primeira, sob o legado malthusiano, defendia que o crescimento populacional se constituía em um entrave ao crescimento econômico (quando a população cresce mais rapidamente em comparação com os recursos disponíveis). A segunda, o crescimento populacional seria benéfico ao crescimento econômico porque fomentaria o consumo e oferece mão de obra (PAIVA; WAJNMAN, 2005).

Alves (2014) afirma que novas discussões sobre população surgiram no decorrer dos anos, entre elas a neomalthusiana. De acordo com os adeptos a essa corrente, a diminuição do crescimento populacional é primordial para o desenvolvimento. Isso porque o número de habitantes é o denominador da equação do PIB per capita e sem a diminuição do denominador não seria possível acontecer aumentos do valor do PIB per capita.

Diferentemente, para Kuznets (1983), é fato que os países modernos que apresentaram aumento sustentado do produto per capita e da população apresentaram maior crescimento econômico. Visto que, na concepção de crescimento econômico moderno é fundamental o aumento da população e do produto per capita. Essa concepção é justificada, pois, para manter um crescimento sustentado do produto per capita, dado o aumento populacional, é necessário aperfeiçoamento do desempenho econômico, e também porque, é a população que produz e que consome essa mesma produção.

A população local, em algumas situações (como de pobreza de recursos naturais), dado seu potencial criativo e diferencial pode modificar uma região tornando-a mais competitiva do que outras. Assim, essa região torna-se atrativa à população superando a dificuldade inicial de crescimento econômico. A expansão do mercado consumidor, da capacidade de gerar emprego estimulará a região a avançar num centro de consumo, distribuição e transformação produtiva (FERRERA DE LIMA, 2016).

Dessa forma, o crescimento populacional pode conter o crescimento, porém, apenas o aumento populacional não pode ser considerado como suficiente para mover o crescimento econômico de uma localidade (FONSECA, 2006). Kuznets (1983) considerou que o crescimento econômico pode ser verificado em regiões nas quais altas taxas de crescimento populacional estiveram presentes, condições de manter o produto e a mesma qualidade de vida ou ligeiramente inferior.

Assim, estudos sobre o processo de crescimento econômico e a dinâmica da população fornecem subsídios para se compreender a capacidade das economias regionais em manterem sua estrutura produtiva e a acumulação de capital ao longo do tempo.

\section{Elementos Metodológicos}

Em 2016, o Paraná possuía uma população estimada em 11 milhões de habitantes distribuídos em uma área total de 199.307,939 km², 
totalizando uma densidade demográfica de 52,40 habitantes $/ \mathrm{km}^{2}$. O estado conta com 399 municípios divididos em 10 mesorregiões e 39 microrregiões geográficas (IBGE, 2016; IPARDES, 2015).

No conjunto do Paraná, a mesorregião Norte Pioneiro é uma das dez mesorregiões paranaenses. Sua colonização se iniciou no século XIX, ainda na época do Império. A ocupação da mesorregião se deu por dois motivos: primeiro, conectar o litoral do Brasil até a Província de Mato Grosso, e segundo, a imigração de fazendeiros mineiros e paulistas que para a região se deslocaram devido a extensas áreas férteis ali encontradas (IPARDES, 2004).

Inicialmente, a estrutura produtiva local estava baseada na atividade cafeeira, o que permitiu que de uma área pouco povoada viesse a se constituir uma das mais ricas e populosas dentre as mesorregiões do Paraná até a segunda metade do século XX, quando a dinâmica local se modifica depois da crise enfrentada pelo setor cafeeiro nos anos de 1970 e pela substituição da cultura do café por outras commodities. A mesorregião teve dificuldades em se adaptar a essas novas culturas e passou a apresentar decréscimo populacional ao longo dos anos de 1980 até 2000. As perdas populacionais atingiram todas as faixas etárias, principalmente, a população mais jovem, acarretando um envelhecimento da população (IPARDES, 2004). Enquanto outras regiões de colonização mais recente avançavam, o Norte Pioneiro entrou em declínio. Atualmente, a mesorregião é composta de 46 municípios e está posicionada em sétimo lugar no ranking do PIB. Assim, compreender a dinâmica do Norte Pioneiro fornece subsídios para se discutir políticas públicas de emprego e renda para essa região. Mais ainda compreender a tendência de declínio e recuperação da sua economia.

Na Figura 1 estão expostas as mesorregiões do estado do Paraná.

Figura 1 - Mesorregióes do Estado do Paraná - 2019.

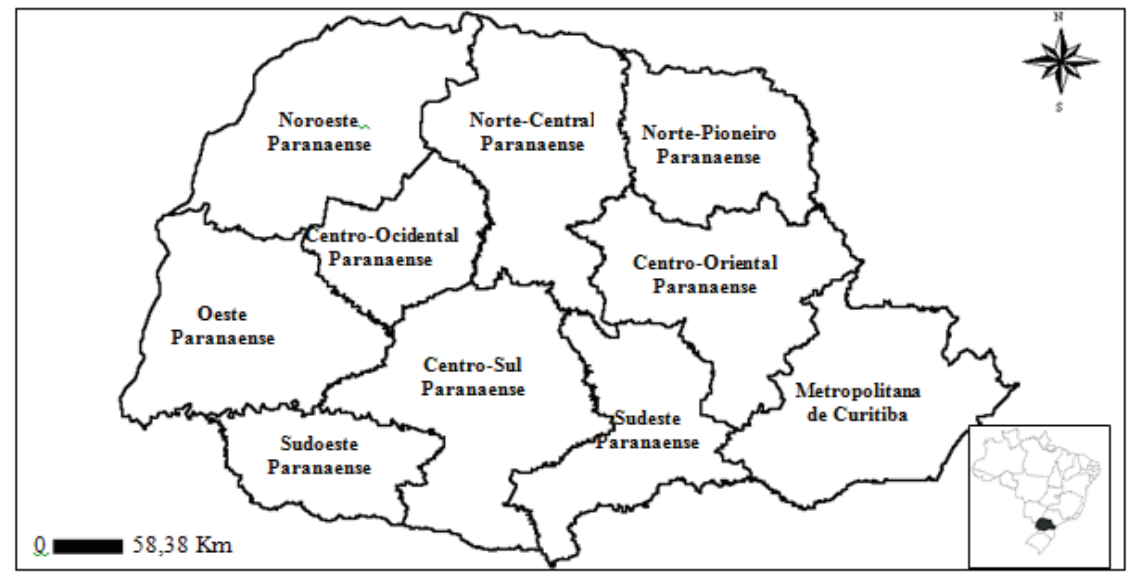

Fonte: IBGE (2019)

Coleta e Tratamento de Dados 
Para a análise do comportamento do PIB das microrregiões que compõe o Norte Pioneiro do estado do Paraná delimitou-se o período temporal que compreende os anos de 2004 a 2014. Foram utilizadas duas variáveis: o PIB a preços correntes e o número de habitantes dos municípios que compõe cada microrregião do Norte Pioneiro do Paraná.

O PIB a preços correntes foi obtido por meio do banco de dados do IPARDES e deflacionado pelo índice de preços do Índice Nacional de Preços ao Consumidor Amplo ${ }^{1}$ (IPCA), utilizou-se como base o ano de 2004. A segunda variável (população residente) foi extraída a partir de dois bancos de dados: os anos de 2007 (contagem oficial da população) e 2010 (censo demográfico) foram retirados do Instituto Brasileiro de Geografia e Estatística (IBGE), e os demais anos foram retirados do banco de dados do IPARDES (estimativas populacionais). O tratamento de dados foi realizado a partir do PIB real, utilizando os seguintes indicadores:

- Participação percentual das mesorregiões geográficas no total do PIB real paranaense:

$$
\begin{aligned}
& \% \text { PIB real meso }=\frac{\text { PIB real Norte Pioneiro Paraná.ano }}{\text { PIB real Paranáano }} \\
& \% \text { PIB real meso }=\frac{\text { PIB real Norte Pioneiro Paraná.ano }}{\text { PIB real Paranáano }}
\end{aligned}
$$

- Participação percentual das microrregiões geográficas no total do PIB real da mesorregião Norte Pioneiro paranaense:

$$
\begin{aligned}
& \text { Part. PIB real micro }=\frac{\text { PIB real micro.ano }}{\text { PIB real Norte Pioneiro Paraná.ano }} \\
& \text { Part. PIB real micro }=\frac{\text { PIB real micro.ano } o_{\mathrm{x}}}{\text { PIB real Norte Pioneiro Paraná.ano }}
\end{aligned}
$$

- Taxa de crescimento do PIB real:

$$
\begin{aligned}
& \Delta \% \text { PIB real ano }{ }_{\mathrm{x}}=\frac{\text { PIBreal ano }_{\mathrm{X}}-\text { PIBreal ano }_{\mathrm{X}-1}}{\text { PIBreal ano }_{\mathrm{X}-1}} \\
& \Delta \% \text { PIB real ano } \\
& \text { PIBreal ano }_{\mathrm{x}}-\text { PIBreal ano }_{\mathrm{X}-1} \\
& \text { PIBreal ano }_{\mathrm{X}-1}
\end{aligned}
$$

- Taxa de crescimento da População:

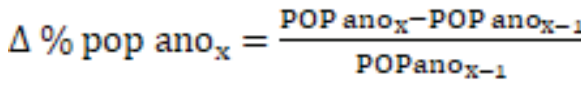

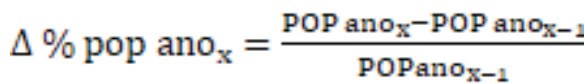

1 De acordo com definições do Instituto Brasileiro de Geografia e Estatística (IBGE) o objetivo é verificar a variação de preço de um conjunto de produtos e serviços utilizados pelas famílias com rendimento de 1 - 40 salários mínimos residentes nas regiões metropolitanas do Rio de Janeiro, Porto Alegre, Belo Horizonte, Recife, São Paulo, Belém, Fortaleza, Salvador e Curitiba, do Distrito Federal e Município de Goiânia. 
- PIB per capita:

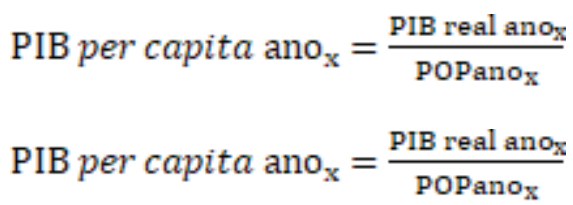

A análise apresentada na próxima seção contempla o crescimento econômico do Norte Pioneiro do estado do Paraná a partir da sua participação no PIB real no total do estado; e da taxa de crescimento do $\mathrm{PIB}$, da população e do PIB per capita das microrregiões, comparando-a com a mesorregião Norte Pioneiro.

\section{Resultados e Discussões}

O Norte Pioneiro representou cerca de 3\% do PIB real paranaense ao longo do período 2004-2014. Destaca-se a participação percentual da região Metropolitana de Curitiba (que ao longo de dez anos representou aproximadamente $44 \%$ do PIB do estado) e da região Norte Central (que representou cerca de $16 \%$ do PIB estadual ao longo dos dez anos). Essas duas regiões juntas representam mais da metade de toda a produção do estado do Paraná (60\%). Os outros 40\% são produzidos por outras oito mesorregiões. Dentro desse contexto, encontra-se a mesorregião Norte Pioneiro do Paraná. Sua participação ao longo do período na produção estadual variou em torno de $3 \%$ do total do PIB real do estado (Figura 2).

A concentração da participação no total do PIB estadual mostra que a região de Curitiba tende a atrair fatores de produção essenciais para o seu crescimento econômico, aumentando sua participação em detrimento às demais localidades. Dessa forma, sua produção tende a ser mais diversificada proporcionando uma troca desigual entre as regiões estaduais. Para Piacenti (2016), a análise regional feita dentro das fronteiras de um país gera implicações, porque existe livre circulação de mercadorias e capital.

No caso da mesorregião Norte Pioneiro, percebeu-se que a dissonância no montante produzido entre as mesorregiões paranaenses permanece internamente entre suas microrregiões geográficas. De acordo com a Figura 3, apenas duas microrregiões - Cornélio Procópio (14 municípios) e Jacarezinho (6 municípios) - se destacaram no que se refere à participação no produto real da economia e na quantidade de pessoas residindo. Existe tendência de manutenção da participação de cada microrregião no PIB e no total de população ao longo dos dez anos. $\mathrm{O}$ crescimento econômico não é homogêneo e existe relação entre a produção e a quantidade de habitantes 
de uma localidade. Assim como Kuznets (1983) explica sobre a existência da desigualdade na distribuição da renda. Também essa realidade foi verificada nas mesorregiões e nas microrregiões do Norte Pioneiro paranaense.

Figura 2. Participação percentual das Mesorregiões Geográficas do Paraná no PIB real do estado em 2004 e 2014 - (R\$ 1.000,00)

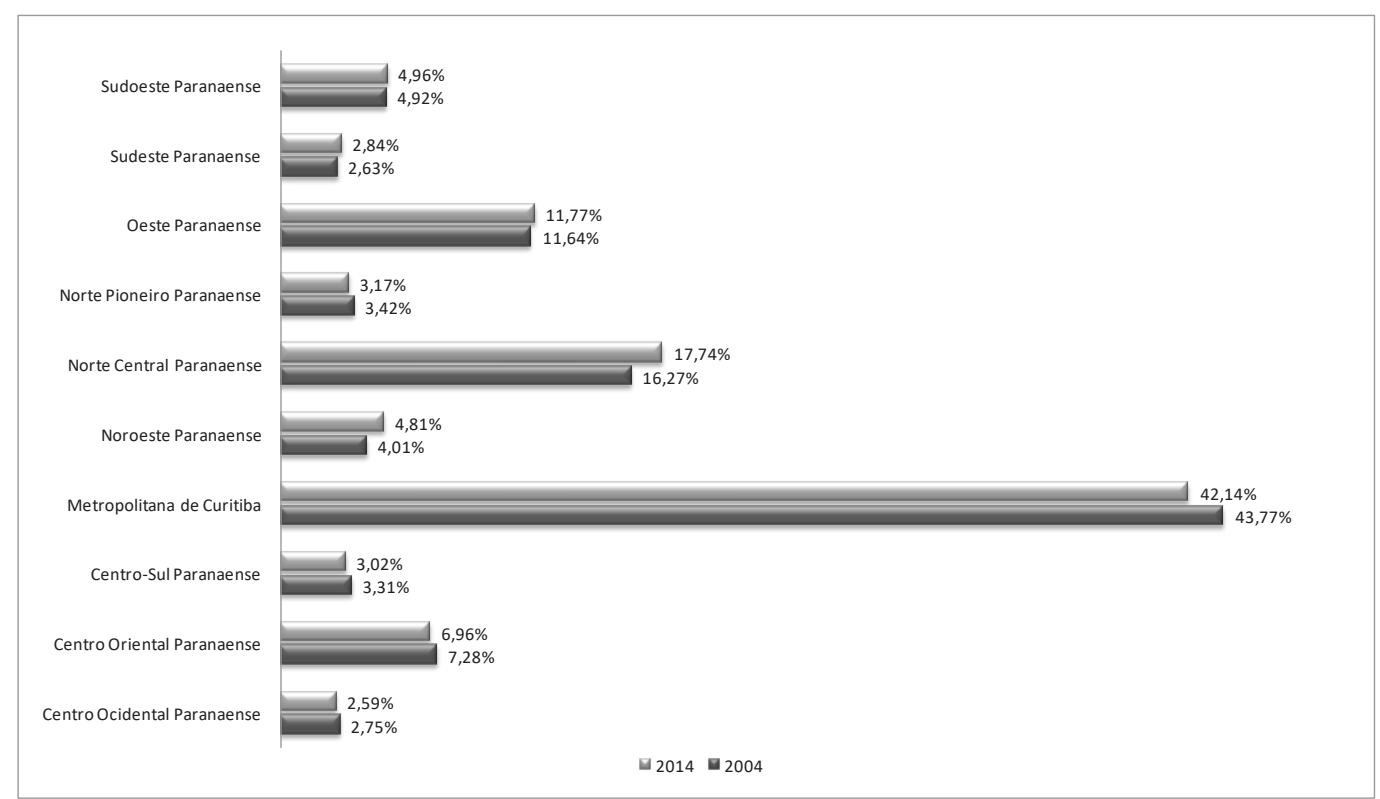

Fonte: Resultados da Pesquisa, 2017 - dados deflacionados IPCA

Figura 3. Participação percentual no total do PIB real e da população residente de cada microrregião do Norte Pioneiro Paranaense de 2004 a 2014

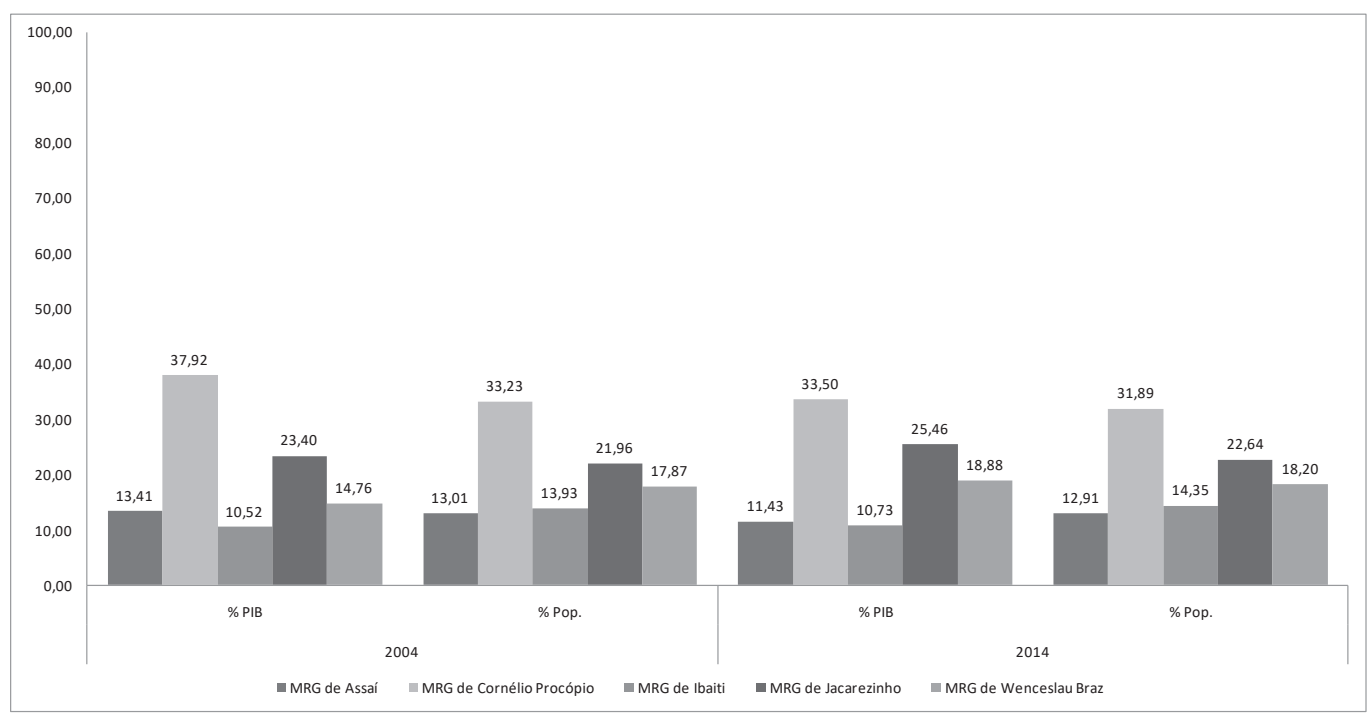

Fonte: Resultados da Pesquisa, 2017 - dados deflacionados IPCA 
2 Valor deflacionado pelo índice IPCA.
Ao longo do período analisado, o crescimento do Norte Pioneiro não apresentou um comportamento linear (Figura 4). Porém, percebeu-se que duas microrregiões merecem destaque no que diz respeito ao desempenho alcançado no PIB: Wenceslau Braz e Jacarezinho. Quando a mesorregião apresentou decréscimo no PIB, essas duas localidades tiveram uma queda menor do PIB do que o conjunto do Norte Pioneiro. Porém, quando a mesorregião cresceu em termos de PIB, elas acompanharam o sentido positivo da variação do PIB. Aliás, Wenceslau Braz foi a única microrregião que apresentou um crescimento do PIB real em todos os períodos. $\mathrm{Ou}$ seja, internamente a economia regional do Norte Pioneiro passa por uma reestruturação com o fortalecimento de Wenceslau Braz.

Ao falar sobre o crescimento econômico apresentado pela microrregião de Wenceslau Braz, quando se observa o Valor Adicionado Bruto Real ${ }^{2}$ no período de 2004 a 2014 (Tabela 1) destacou-se o crescimento apresentado pela indústria e comércio e serviços. Já Jacarezinho apresentou expansão na administração pública e comércio e serviços.

Tabela 1 - Valor adicionado bruto real das microrregiões do Norte Pioneiro 2004 a 2014

\begin{tabular}{llccc}
\hline \multicolumn{1}{c}{ Microrregião } & \multicolumn{1}{c}{ Setor } & $\mathbf{2 0 0 4}$ & $\mathbf{2 0 1 4}$ & Variação \\
\hline Assaí & Agropecuária & 187.457 & 163.474 & $-13 \%$ \\
Assaí & Indústria & 79.059 & 86.010 & $9 \%$ \\
Assaí & Comércio e Serviços & 179.953 & 292.017 & $62 \%$ \\
Assaí & Administração Pública & 85.608 & 155.363 & $81 \%$ \\
Cornélio Procópio & Agropecuária & 437.752 & 370.388 & $-15 \%$ \\
Cornélio Procópio & Indústria & 260.516 & 314.132 & $21 \%$ \\
Cornélio Procópio & Comércio e Serviços & 577.914 & 953.652 & $65 \%$ \\
Cornélio Procópio & Administração Pública & 210.443 & 380.318 & $81 \%$ \\
Ibaiti & Agropecuária & 127.323 & 196.022 & $54 \%$ \\
Ibaiti & Indústria & 55.988 & 71.323 & $27 \%$ \\
Ibaiti & Comércio e Serviços & 146.903 & 234.271 & $59 \%$ \\
Ibaiti & Administração Pública & 86.431 & 163.227 & $89 \%$ \\
Jacarezinho & Agropecuária & 191.792 & 237.263 & $24 \%$ \\
Jacarezinho & Indústria & 214.190 & 361.684 & $69 \%$ \\
Jacarezinho & Comércio e Serviços & 371.501 & 661.815 & $78 \%$ \\
Jacarezinho & Administração Pública & 134.963 & 262.671 & $95 \%$ \\
Wenceslau Braz & Agropecuária & 187.899 & 257.621 & $37 \%$ \\
Wenceslau Braz & Indústria & 70.964 & 184.831 & $160 \%$ \\
Wenceslau Braz & Comércio e Serviços & 206.473 & 484.498 & $135 \%$ \\
Wenceslau Braz & Administração Pública & 109.988 & 209.787 & $91 \%$ \\
\hline
\end{tabular}

Fonte: Resultados da Pesquisa, 2017 - dados deflacionados IPCA.

A microrregião de Assaí demonstrou um comportamento bastante frágil em relação à economia regional, por exemplo, quando a taxa de crescimento do Norte Pioneiro foi negativa, Assaí caiu mais do que a região de referência. Já quando, o Norte Pioneiro apresentou taxa de crescimento positiva, a Assaí cresce mais do que a região de referência.

A observação do valor adicionado da microrregião de Assaí permite identificar que a agricultura apresentou uma retração no período 
analisado. Verificou-se também que a indústria nessa microrregião foi o ramo de atividade da mesorregião Norte Pioneiro que apresentou o menor crescimento.

Cornélio Procópio apresentou também comportamento bastante frágil quando comparado à mesorregião Norte Pioneiro. Percebe-se que assim como Assaí, essa microrregião apresentou retração da agricultura no período de 2004 a 2014. Ou seja, a economia de Assaí e Cornélio Procópio está fortemente vinculada ao desempenho da economia do conjunto da região e também são as mais fragilizadas frente aos ciclos regionais. Isso surpreende, pois Cornélio Procópio é o polo regional.

Quando se analisam as taxas de crescimento do PIB real (Figura 4) comparando com as taxas de crescimento da população (Figura 5) visualizam-se comportamentos semelhantes para a maior parte do período. Até 2008 a taxa de crescimento do PIB real foi crescente ano a ano para o conjunto da mesorregião analisada, caindo em 2009.

Figura 4 - Taxa de crescimento do PIB real das microrregióes que compõem o Norte Pioneiro Paranaense de 2004 a 2014

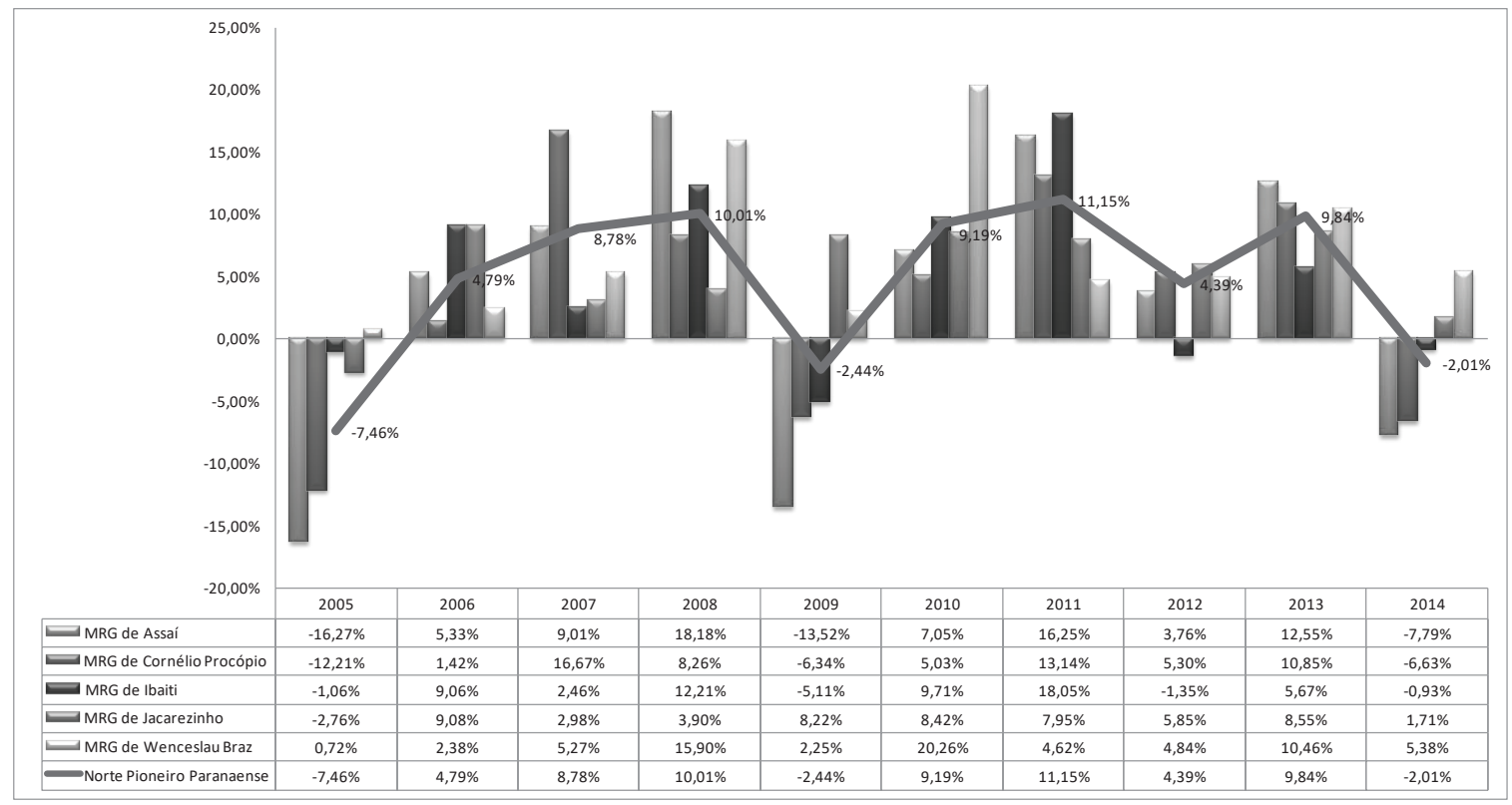

Fonte: Resultados da Pesquisa, 2017 - dados deflacionados IPCA

Fato interessante ocorreu com a taxa de crescimento da população. Infelizmente nos dados da população tem-se informações de Censos Demográficos (2010) e da contagem oficial da população (2007) e estimativas populacionais (demais anos, coletados do IPARDES). Essas diferenças de coleta/estimativa da população influenciaram nos valores absolutos e nas variações discrepantes em alguns anos, como no ano de 2007 
em relação ao ano de 2006, pois foi analisada a contagem da população a partir de uma estimativa.

Entretanto, a despeito dessas diferenças metodológicas, é possível verificar uma semelhança parcial das variações da população com relação às variações do PIB real. Em todos os picos de crescimento do PIB (2008, 2011 e 2013) também ocorreu crescimento (ou redução do ritmo de diminuição) da população. Esses fatos reforçam a existência de uma relação direta entre população e crescimento econômico. De acordo com Ferrera de Lima (2016), o crescimento e o diferencial apresentado por uma região pode constituir-se pela capacidade da população local e tornarse um estímulo para atração de novos habitantes para a região. Kuznets (1983) destacou o fato de algumas regiões que apresentaram aumento sustentado do produto per capita e da população apresentaram também maior crescimento econômico.

Figura 5 - Taxa de Crescimento da população residente das microrregiões que compõe o Norte Pioneiro Paranaense de 2004 a 2014

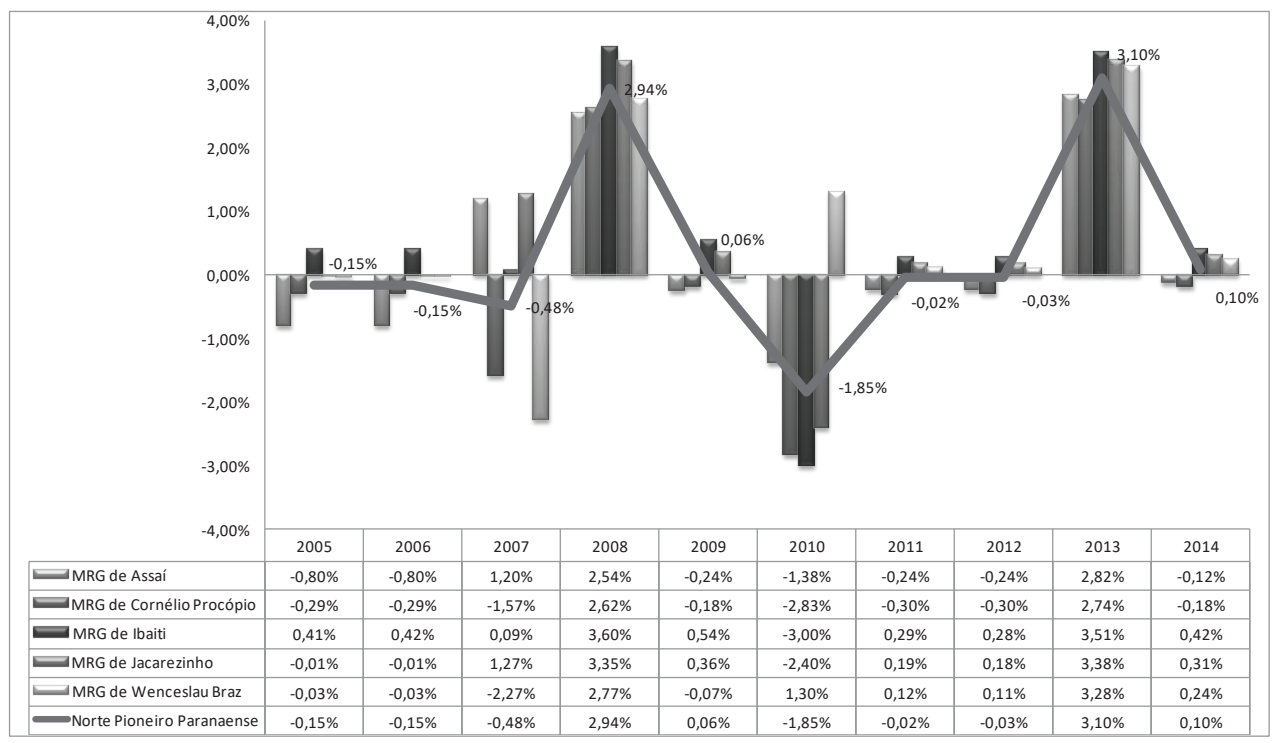

Fonte: Elaboração própria (2017)

Até o momento, foram apresentados os aspectos quantitativos relacionados ao $\mathrm{PIB}$, ou seja, foi tratado sobre o crescimento. A partir de agora, será abordado o aspecto qualitativo, relacionado ao dinamismo dessas regiões, ou seja, a capacidade de manter ou apresentar crescimento do PIB per capita dada variação populacional. Para isso, a Figura 6 apresenta a evolução do PIB real per capita para cada microrregião que compõe o Norte Pioneiro, sendo assim algumas considerações são necessárias para o melhor entendimento da realidade. 
Figura 6 - Evolução do PIB Real per capita das microrregiões que compõe a mesorregião geográfica Norte Pioneiro Paranaense de 2004 a 2014

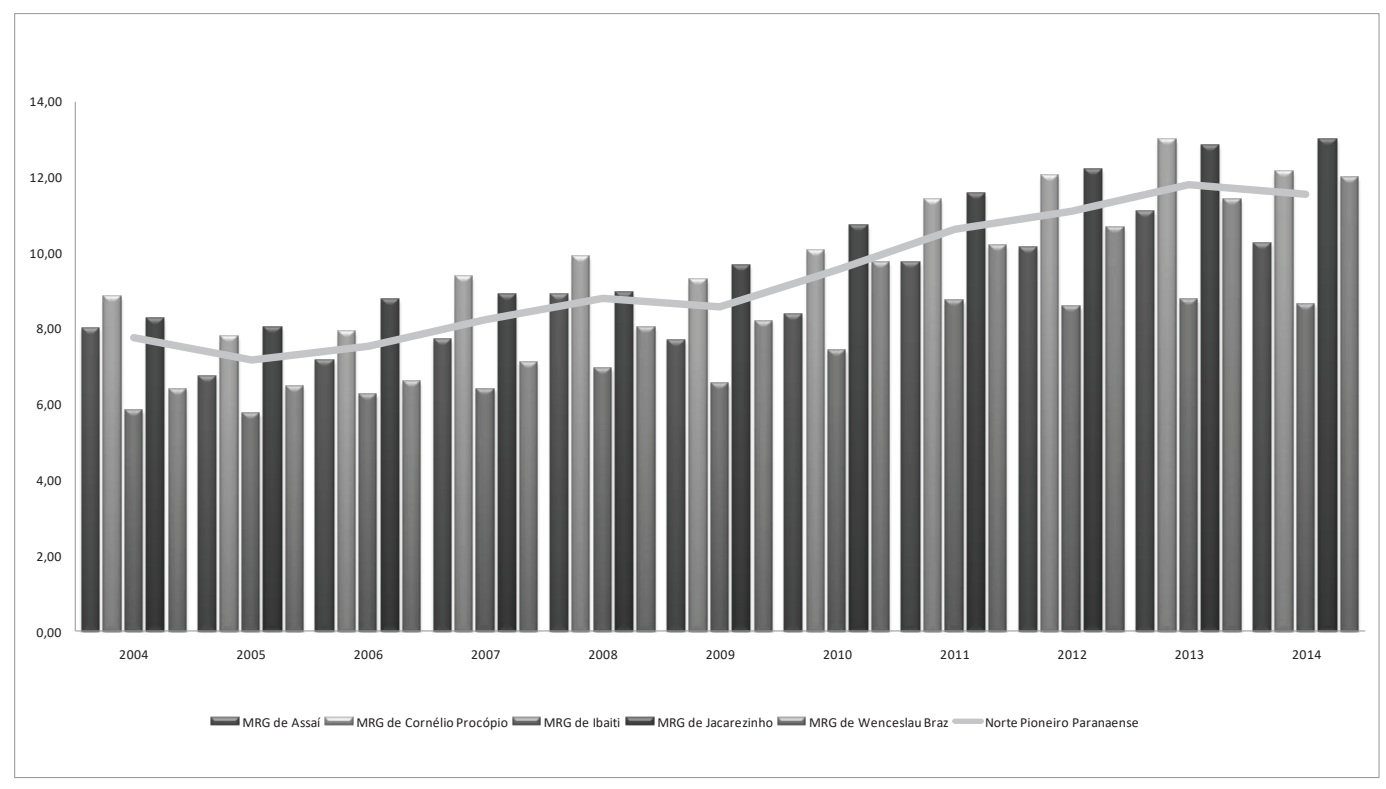

Fonte: Resultados da Pesquisa, 2017 - dados deflacionados IPCA

Apenas duas microrregiões apresentaram PIB per capita acima da média da mesorregião: Cornélio Procópio e Jacarezinho. Essas microrregiões encontraram uma fonte de crescimento, e podem ser consideradas microrregiões mais dinâmicas dentro da mesorregião Norte Pioneira do Paraná. Observa-se como a microrregião menos dinâmica a de Ibaiti.

Percebe-se também que quando o crescimento populacional apresenta picos de crescimento (2008 e 2013), o PIB per capita tem um crescimento acentuado. Já quando o crescimento populacional caiu (2008 para 2009) o PIB per capita também diminuiu. Esse resultado corrobora com Kuznets (1983), pois para a concepção de crescimento econômico moderno é primordial o aumento da população e do produto per capita. Uma vez que a manutenção do crescimento do produto per capita dado o aumento populacional exige aperfeiçoamento do desempenho econômico; e essa população é responsável pela produção e consumo dessa riqueza. Ferrera de Lima (2016) aponta o fato de que é a população local, dado seu potencial criativo que pode modificar uma região tornando-a mais competitiva do que outras.

\section{Conclusão}

O objetivo deste artigo foi analisar o crescimento econômico da mesorregião geográfica Norte Pioneiro do Paraná a partir da análise do PIB real e da população residente para o período de 2004 e 2014. Para isso 
foram analisados dados do PIB e da dinâmica populacional no conjunto da mesorregião e das suas microrregiões.

Com os resultados da pesquisa foi possível observar que o crescimento econômico do Norte Pioneiro arrefeceu. No caso das microrregiões, somente Wenceslau Braz apresentou um desempenho mais significativo em termos crescimento econômico

No seu conjunto, o Norte Pioneiro perdeu participação no PIB estadual e possui uma baixa participação no PIB real estadual se comparado com as demais mesorregiões paranaenses. Para as regiões serem classificadas como desenvolvidas primeiramente ela teria que melhorar seus indicadores socioeconômicos, além de produzir e acumular riqueza. Isso, a princípio, já se constitui em um entrave tanto para o fortalecimento do desenvolvimento do Norte Pioneiro, haja vista que a sua dinâmica econômica apresentou um baixo desempenho.

Quanto à evolução do PIB per capita, percebe-se uma tendência de ascensão do seu montante. Assim, apesar da pouca participação da mesorregião no PIB real do estado, a expansão do PIB per capita foi influenciada pela perda populacional. Quanto à microrregião que apresenta menor PIB per capita destaca-se Ibaiti, e com o maior PIB per capita destacaram-se a de Jacarezinho e Cornélio Procópio.

Atualmente, muitos municípios e regiões têm buscado alternativas de desenvolvimento por meio do fortalecimento dos ativos territoriais. Esses ativos são os elementos que compõem o folclore, o meio ambiente e particularidades da estrutura produtiva, como a gastronomia regional, produtos com selo de indicação geográfica ou certificação de origem. $\mathrm{Ou}$ seja, para regiões pouco atrativas a capitais externos, fortalecer potenciais negócios locais é uma estratégia para se avançar no crescimento e no desenvolvimento econômico. Essa parece ser uma alternativa para o Norte Pioneiro se reposicionar na economia paranaense.

Fica como sugestão para novos estudos detectar qual o perfil da população residente em Ibaiti de forma que possa identificar se existe na população algum entrave para o seu crescimento, como por exemplo, elevado número de pessoas em idade não produtiva.

\section{Referências}

ALVES, J. E. D. População, desenvolvimento e sustentabilidade: perspectivas para a CIPD pós-2014. Revista Brasileira de Estudos Populacionais, Rio de Janeiro, v. 31, n. 1, p. 219-230, jun. 2014.

BERLINCK, M. T.; COHEN, Y. Desenvolvimento econômico, crescimento econômico e modernização na cidade de São Paulo. Revista de Administração de Empresas, Rio de Janeiro, v. 10, n. 1, p. 45-64, jan./mar. 1970.

FERRERA DE LIMA, J. La diffusion spatiale du développement économique régional. Sarrabruc: EUE, 2010. 
FERRERA DE LIMA, J. O espaço e a difusão do desenvolvimento econômico regional. In: PIACENTI, C. A.; FERRERA DE LIMA, J. ; EBERHARDT, P. H. de C. (org.). Economia e desenvolvimento regional. Foz do Iguaçu: Parque Itaipu, 2016. p. 15-40.

FONSECA, M. A. R. da. Planejamento e desenvolvimento econômico. São Paulo: Thomson, 2006.

INSTITUTO BRASILEIRO DE GEOGRAFIA E ESTATÍSTICA (IBGE). IBGE Cidades. [2019]. Disponível em: https://cidades.ibge.gov.br/v4/brasil/pr. Acesso em: 26 maio 2017.

INSTITUTO BRASILEIRO DE GEOGRAFIA E ESTATÍSTICA (IBGE). Download: cartas e mapas. [2019]. Disponível em: http://www2.ibge.gov.br/pub/ Cartas_e_Mapas/Cartogramas/Municipios_Micro_e_Mesorregioes/.Acesso em: 3 set. 2019.

INSTITUTO BRASILEIRO DE GEOGRAFIA E ESTATÍSTICA (IBGE). Sistema Nacional de Índices de Preços ao Consumidor (SNIPC). 2017. Disponível em: http://www.ibge.gov.br/home/estatistica/indicadores/precos/ inpc_ipca/informet.shtm. Acesso em: 29 jun. 2017.

INSTITUTO BRASILEIRO DE GEOGRAFIA E ESTATÍSTICA (IBGE). Diretoria de pesquisas, coordenação de trabalho e rendimento, pesquisa nacional por amostra de domicílios contínua 2016. 2016. Disponível em: http:// www.ibge.gov.br/estadosat/perfil.php?lang=\&sigla=pr. Acesso em: 29 jun. 2017.

INSTITUTO PARANAENSE DE DESENVOLVIMENTO ECONÔMICO E SOCIAL (IPARDES). Leituras Regionais - Mesorregião Geográfica Norte Pioneiro Paranaense. Curitiba: IPARDES, 2004. Disponível em: http://www. ipardes.gov.br/biblioteca/docs/leituras_reg_meso_norte_pioneiro.pdf. Acesso em: 30 jun. 2017.

INSTITUTO PARANAENSE DE DESENVOLVIMENTO ECONÔMICO E SOCIAL (IPARDES).Paraná em Números. Curitiba:Ipardes, 2015.Disponível em: http://www.ipardes.gov.br/index.php?pg_conteudo=1\&cod_conteudo=1. Acesso em: 30 jun. 2017.

KUZNETS, S. Crescimento Econômico Moderno: ritmo, estrutura e difusão. São Paulo: Abril Cultural, 1983.

LACOUR, C.; GACHET, F. Métropolisation, centre et centralité. Revue D'Économie Régionale et Urbaine, [s.l.], n. 1, p. 49-72, 2002.

MANSANO, F. H.; PEREIRA, M. F. A importância da região norte na economia paranaense. A Economia em Revista, [s.l.], v. 24, n. 1, p. 103-117, jul. 2015.

PADIS, P. C. Formação de uma economia periférica: o caso do Paraná. São Paulo: Hucitec, 1981.

PAIVA, P. de T. A.; WAJNMAN, S. Das causas às consequências econômicas da transição demográfica no Brasil. Revista Brasileira de Estudos de População, São Paulo, v. 22, n. 2, p. 303-322, jul./dez. 2005.

PAludO, G. B.; BARROS, D. A. Síntese da História do Paraná. Cascavel: Assoeste, 1995. 
PIACENTI, C. A.. O desenvolvimento endógeno das regiões. In: PIACENTI, C. A.; LIMA, J. F. de; EBERHARDT, P. H. de C. (org.). Economia e Desenvolvimento Regional. Foz do Iguaçu: Parque Itaipu, 2016. p. 122-141.

SILVA, M. Pobreza e desenvolvimento humano. In: SILVA, M. (org.) Desenvolvimento econômico e repartição do rendimento. Lisboa: Impressa Universitária n. 28, Editorial Estampa, 1983. p. 28-46.

Submetido: $22 / 07 / 2019$

Aceito: 09/10/2020 


\title{
ECONOMIC AND POPULATION GROWTH OF THE PARANÁ PIONEER NORTH MESOREGION, FROM 2004TO 2014
}

\begin{abstract}
Economic growth is verified when, due to high rates of population growth, conditions were maintained to maintain the product and quality of life. This article had as scope to analyze the economic growth of the Northern Pioneer mesoregion of Paraná from the analysis of Gross Domestic Product - GDP and population growth for the years 20042014. For this, indicators were calculated using real GDP and the resident population variable. The results indicate that economic growth attracts population or neutralizes the emigration process. Some microregions, belonging to the aforementioned mesoregion, have found a way to boost their economy by providing sustained growth.
\end{abstract}

Keywords: Economic Growth. Population. Investment. Attraction.

\section{CRECIMIENTO ECONÓMICO Y POBLACIONAL DEL PIONERO DEL PARANÁ MESOREGIÓN NORTE, DE 2004 A 2014}

\begin{abstract}
Resumen
El crecimiento económico se verifica cuando, debido a las altas tasas de crecimiento de la población, se mantuvieron las condiciones para mantener el producto y la calidad de vida. Este artículo tuvo el alcance de analizar el crecimiento económico de la mesorregión Pioneer Norte de Paraná a partir del análisis del Producto Interno Bruto - PIB y crecimiento de la población para los años 2004-2014. Para ello, los indicadores se calcularon utilizando el PIB real y la variable de población residente. Los resultados indican que el crecimiento económico atrae a la población o neutraliza el proceso de emigración. Algunas microrregiones, pertenecientes a la mencionada mesorregión, han encontrado una manera de impulsar su economía al proporcionar un crecimiento sostenido.
\end{abstract}

Palabras clave: Crecimiento econômico. Poblacion. Inversión. Atraccion 